\title{
Introduction: the brain and aggression: a bioethical dimension of aggression and violence*
}

\author{
Roberto E. Mercadillo and J. Martín Ramírez
}

This section is a selection of the papers presented at the 15th International Colloquium on the Brain and Aggression, held in Mexico City in September 2007, focusing on a bioethical dimension of aggression and violence.

The United Nations has aimed from the outset, to establish genuine peace among and between peoples on the basis of the consensus to identify universal human rights and to limit violence and oppression. The preamble to the Charter of the United Nations accordingly states: "We the peoples of the United Nations determined ... to save succeeding generations from the scourge of war". Drawing on the abovementioned preamble, on the occasion of the World Congress on Aggression held in Mexico City in 1982, an interdisciplinary group of scientists established a working group under the name, "The International Colloquium on the Brain and Aggression (CICA)", with the goal of elucidating, in the light of modern scientific discoveries, whether violence

Roberto E. Mercadillo was Coordinator of the $15^{\text {th }}$ International Colloquium on the Brain and Aggression (CICA), Mexico City and works at the National School of Anthropology and History, Mexico City. Email: xofiel@hotmail.com

J. Martín Ramírez is Chair of the International Colloquium on the Brain and Aggression. He is a member of the Complutense Research Group on Aggression, Institute of Biofunctional Studies and the Department of Psychobiology, Complutense University of Madrid, and the International Security Programme, Belfer Centre for Science and International Affairs, Kennedy School of Government, Harvard University.

Email:mramirez@med.ucm.es and war were an inevitable part of human nature or whether, conversely, human beings could manage conflict peacefully. After 4 years of study 29 scientists from 13 countries met in Seville, Spain, in May 1986, under CICA's auspices, to finalise the draft compilation of their arguments. The document, known as the Seville Statement on Violence, was adopted by the General Conference of UNESCO held in established CICA, whose work at the behest of the international scientific community has been showcased in various cities in Africa, the Americas, Asia and Europe, was marked in 2007. The 15th CICA, organised by the National Autonomous University of Madrid, the UNESCO Chair for Human Rights in Mexico and the Complutense University of Madrid, was held in Mexico City, the venue at which it had originally convened. 
The 15th CICA was premised on two assumptions: that the establishment of a culture of peace requires a holistic approach to the prevention of social conflicts and that it constitutes an alternative to war and violence. This proposition can only rest on knowledge of the political, social, economic and biological causes of violent behaviour in particular and of society as a whole.

Drawing on these assumptions, the 25th CICA analysed aggression and violence from a bioethical standpoint and revised the Seville Statement on Violence in the light of new scientific findings. In view of the interdisciplinarity required to address the issue of violence the Colloquium was attended not only by speakers from diverse biological fields such as neuropsychology, medicine and biology but also by experts from social, humanistic and political spheres.

Bioethics, which forms part of behavioural studies in which violence is addressed, differs from other disciplines in several ways. The data obtained, the interpretation of research studies and the general idea of specific links between biology and behaviour from which they are derived help to shape our view of human beings, their "nature", being and development. That view of ourselves and of our supposed nature is in turn linked, unconsciously or deliberately, to the way in which we build the conceptual framework within which we formulate our working assumptions and interpret results when they are being verified.

The bioethics of human behaviour is therefore important if we are to be fully aware of the existence of reciprocal links between our personal subjective convictions and the objective field of science because we are basically interested, as researchers, in understanding the determinants of human behaviour and personality in greater depth. Admittedly, we occasionally place emphasis on only one part of the results but the true weight and real influence of our personal convictions become evident when, on the basis of the same set of data, we address the issue of human aggression and violence. Some results convey a message of necessity and inevitability, while others stress a message of freedom, responsibility and hope.

The articles below contain some of the representative proposals made at the 15 th CICA. Drawing on our awareness as members of the scientific community, we have shared opinions with biological and social experts to provide a holistic view of aggression and violence in these articles. Although some articles concentrate on empirical results in the fields of neuroscience and animal behaviour they are explicitly designed to provide insights into violence and human societies. The five articles are therefore an epistemological attempt to understand the human being as a bio-psycho-social organism.

These psychobiological and psychosocial interpretations are therefore a tool for use in the social sciences and the first step in the interdisciplinary debate that must be held in order to redefine human behaviour, in particular violence and peace.

Translated from Spanish

\section{Acknowledgements}

*We thank the following bodies for their financial support for the 15th International Colloquium on the Brain and Aggression (CICA), held in Mexico City: the National Council on Science and Technology in Mexico, under cooperation agreement No. 10101/ 230/07; the Institute of Anthropological Research,
Autonomous University of Mexico; UNESCO Chair for Human Rights in Mexico at the Autonomous University of Mexico; the Spanish Agency for Cooperation, Embassy of Spain in Mexico and the Italian Institute of Culture, Embassy of Italy in Mexico. 